九州大学学術情報リポジトリ

Kyushu University Institutional Repository

\title{
Source Apportionment of Heavy Metals in the Sediments of Hongfeng Lake, China
}

Jiang, Hong

State Key Laboratory of Environmental Criteria and Risk Assessment, Chinese Research Academy of Environmental Sciences | College of Water sciences Beijing Normal University

A, Yinglan

College of Water sciences Beijing Normal University

Kitano, Masaharu

Bioproduction Environmental Sciences, Agro-environmental Sciences, Faculty of Agriculture, Kyushu University

Fu, Qing

State Key Laboratory of Environmental Criteria and Risk Assessment, Chinese Research Academy of Environmental Sciences

他

https://doi.org/10.5109/22072

出版情報: 九州大学大学院農学研究院紀要. 57 (1)，pp. 195-199，2012-02. Faculty of Agriculture， Kyushu University

バージョン：

権利関係 : 


\title{
Source Apportionment of Heavy Metals in the Sediments of Hongfeng Lake, China
}

\author{
Hong JIANG ${ }^{1}$, Yinglan $\mathbf{A}^{2}$, Masaharu KITANO, Qing FU ${ }^{1}$, \\ Guoqiang WANG ${ }^{2}$ and Binghui ZHENG $^{1 *}$
}

\author{
Laboratory of Agricultural Metorology, Division of Bioproduction Environmental Sciences, \\ Department of Agro-environmental Sciences, Faculty of Agriculture, \\ Kyushu University 6-10-1 Hakozaki, Fukuoka 812-8581, Japan \\ (Received October 31, 2011 and accepted November 9, 2011)
}

\begin{abstract}
Based on the chemical mass balance (CMB) model, the heavy metals deposited in the bottom sediment of Hongfeng Lake were apportioned to the tributaries and point sources. The results showed that contribution proportion of tributaries serving as non-point sources was much higher than that of point sources. The main sources contributing to the heavy metals in sediments of Hongfeng Lake were Houliu River (about $39 \%$ in upstream source combination and $60 \%$ in estuary source combination) and Maiweng River (about $45 \%$ in upstream source combination and $29 \%$ in estuary source combination).

For the heavy metals in sediment identified as heavily enriched by man-made effluents, the source apportionment results showed that $H_{g}$ was from the estuary area of Maiweng River; $T_{i}$ and $A_{s}$ pollutants were mainly Maiweng River and Houliu River. The concentration of $C_{d}$ well reflected the surrounding land uses because its limited transportation distance. The source apportionment analyses for Hongfeng Lake were helpful for water protection and pollution control management in this region.
\end{abstract}

Key words: chemical mass balance model, Hongfeng Lake, source apportionment, heavy metal, sediment

\section{INTRODUCTION}

Human activities combined with changes in land use pattern like urbanization, agricultural and mining practices are causing serious water quality problems (Wang et al., 2010, 2011). Lake environments are subjected to heavy metal contamination via inputs from main natural, industrial, urban sources and atmospheric deposits that are transported through river discharge and eolian processes (Prange and Dennison, 2000; Radenac et al., 2001). Heavy metals could be absorbed from the water column onto surfaces of fine particles and usually move thereafter with the sediments (Salomons and Fostner, 1984). Sediments can act as a true "sink" for these xenobiotics, making the analytical determination of their concentrations easier (Burton, 1992).

Identification of source and quantification of source contribution to heavy metal in sediment are useful for evaluating the impacts of different pollution sources on the water quality of local receiving waters. However, there are seldom researches focusing on the source apportionment analysis of water pollutions. Su et al., (2011) identified four potential sources (domestic sewage and agricultural pollution, industrial wastewater pollution, mineral weathering, vehicle exhaust and sand mining) and their respective contributions to Qiantang River in China using neural-based modeling and multivariate statistical methods. Chemical mass balance (CMB) model has been widely used for pollutant source apportionment

${ }^{1}$ State Key Laboratory of Environmental Criteria and Risk Assessment, Chinese Research Academy of Environmental Sciences, Beijing 100012, China

${ }^{2}$ College of Water sciences Beijing Normal University, Xinjiekouwai Street 19, Beijing 100875, China

* Corresponding author: Binghui Zheng (E-mail: zhengbh@ craes.org.cn) in air (Cooper and Watson, 1980; Hopke, 1985; Lee et al., 1993; Larsen and Baker, 2003; Gummeneni et al., 2011). However, few works have used the CMB model in simulating water pollutions. Gummeneni et al. (2011) demonstrated that the CMB model can be applied to water materials, such as sediment and wastewater, source apportionment to upper point or non-point sources. Kelley and Nater (2000) also reported a set of certain assumptions can be met when utilizing the CMB model to apportion sediment. Actually, data requirements for source apportionment in the lake sediments are similar to the modeling of ambient pollution concentrations in air (Fay and Rosenzweig, 1980; Gordon et al., 1984). The advantage in modeling lake sediments as opposed to airborne particulates is that the number of potential sources is limited and convenient to know. Main tributaries are potential man-made sources for heavy metal in sediment because it is a receptor of by-products of different human activities at its basin area (Yamamuro and Kanai, 2005) and transports them with sediments to lake. In addition, point sources surrounding lake body are another man-made potential sources contributing to heavy metal to lake through direct inputs or surface runoff.

The main objective of this study is to identify the pollution sources of sediment heavy metals and their contribution proportions in Hongfeng Lake. Hongfeng Lake serves as the drinking water source for the Guiyang city and is sensitive to effluents received from its tributaries and surrounding point sources. In this study, the sediment contamination by heavy metals is evaluated to distinguish different contributions. The chemical mass balance (CMB) model is used for apportioning the 9 monitored heavy metals $\left(C_{d}, C_{r}, T_{i}, F_{e}, M_{n}, C_{u}, P_{b}, A_{s}\right.$ and $\left.H_{g}\right)$ in the sediments from Hongfeng Lake to sources. The analysis results can provide support for taking effective 
remedial actions against heavy metal pollution in the Hongfeng Lake.

\section{MATERIALS AND METHODS}

\section{Study area}

Hongfeng Lake is the largest karst lake located at the Yungui highland (E106 $33^{\prime}-106^{\circ} 47^{\prime}$, N26 $23^{\prime}-26^{\circ} 41^{\prime}$ ) (see Figure 1). The storage capacity of Hongfeng Lake is about 0.6 billion $\mathrm{m}^{3}$, and it serves as the main drinking water source for the Guiyang city. The catchment of Hongfeng Lake is dominated by bare rocky landscape. The region of Hongfeng Lake is affected by humid subtropical monsoon climate, which has warm, dry winter and cool, moist summer due to low latitude and high altitude.

\section{Sites location and samples analysis}

In order to investigate the potential sources of heavy metals, the catchment of Hongfeng Lake was firstly divided into 4 sub-catchments, that is, Maiweng River, Yangchang River, Maxian River and Houliu River subcatchments. The sampling sites were selected to identify the potential contributions of tributaries and point sources to the heavy metal pollutions. Figure 1 shows the locations of sampling sites. Sediment samples were collected in November 2010 and December 2011, respectively, at the sampling sites using Grab sampler for analyzing the heavy metals. Sediment samples collected from downstream areas of main tributaries, lake inlets and sewage draining exits were regarded as potential fitting sources. Sediment samples collected from the site at the lake center were used as receptor. After collection, the sediment samples were stored in acid cleaned polyethylene bottles and frozen $\left(-20^{\circ} \mathrm{C}\right)$. Thereafter, samples were dried in freeze-dryer, and then sieved to pass $63 \mu \mathrm{m}$ and homogenized. Samples were digested in microwave digestion system with $\mathrm{HNO}_{3}-\mathrm{HF}-\mathrm{HClO}_{4}-\mathrm{HCl}$ acid mixture solutions (UNEP, 1982, 1985). Inductively Coupled Plasma Atomic Emission Spectrometry (ICPAES) was used to determine $C_{r}, C_{u}, B_{a}, F_{e}, M_{n}, P_{b}$ and $T_{i}$ after pretreatment using acid digestion. $C_{d}$ levels were detected by using graphite furnace atomic absorption spectrophotometer. The concentrations of $A_{s}$ and $H_{g}$ were determined using atomic fluorescence spectrometry. The analytical calculations were done by employing standard calibration curves. The detection limits for the tested heavy metals are listed in Table 1.

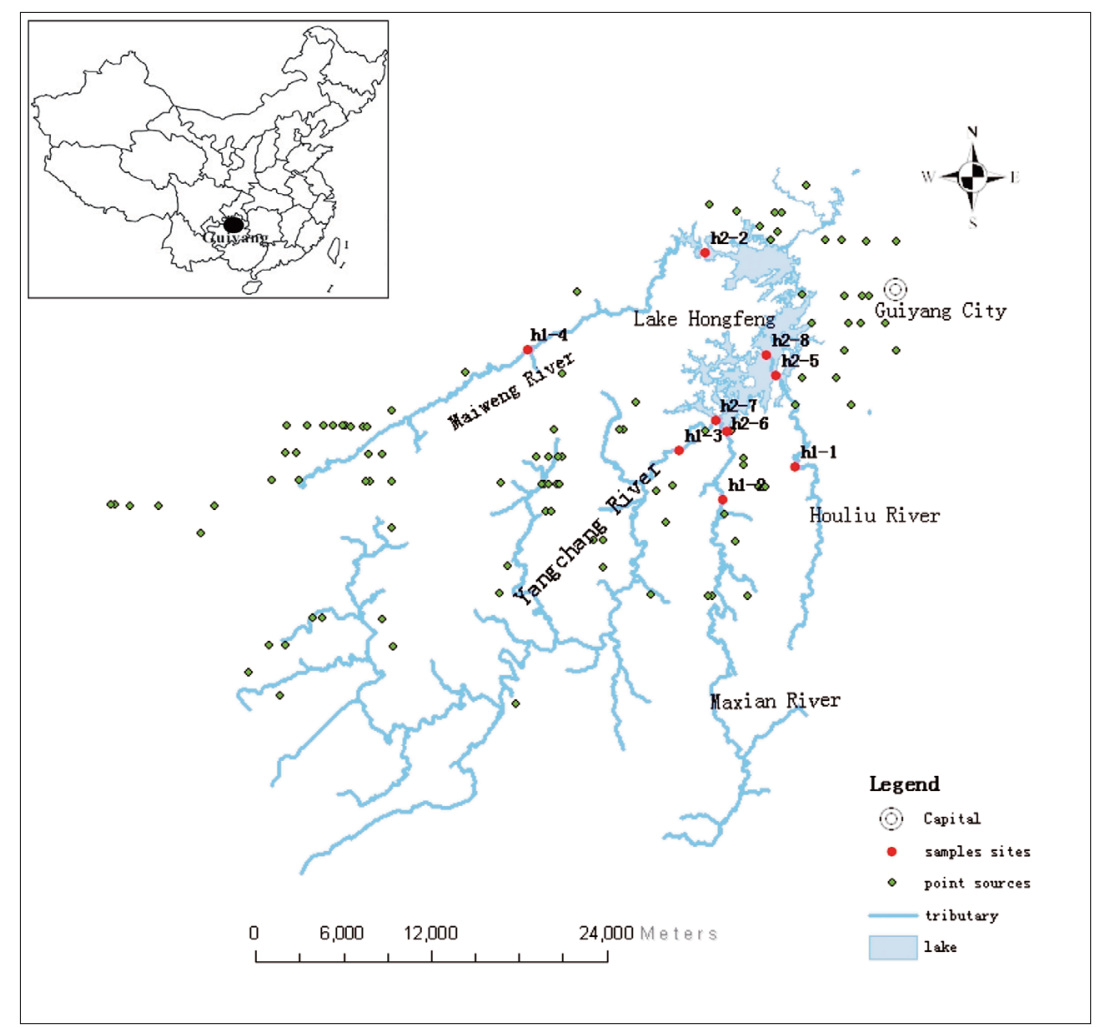

Fig. 1. Locations of point sources and sampling sites.

Table 1. The detection limits of heavy metals in sediment

\begin{tabular}{ccccccccc}
\hline$C_{r}$ & $C_{u}$ & $F_{e}$ & $M_{n}$ & $P_{b}$ & $T_{i}$ & $A_{s}$ & $H_{g}$ & $C_{d}$ \\
\hline 0.06 & 0.03 & 0.05 & 0.06 & 0.1 & 0.1 & 0.5 & 0.0001 & 0.0005 \\
\hline
\end{tabular}




\section{The chemical mass balance model}

The chemical mass balance (CMB) model developed by the US Environmental Protection Agency (EPA) is used for apportioning the heavy metals detected in the sediment samples of Hongfeng Lake to tributaries and point sources.

The governing equation of CMB model is as follows:

$$
C_{i}=\sum_{j=1}^{p} a_{i j} S_{j}, \quad i=1, n
$$

$C_{i}$ is the ambient concentration of species $i$; $a_{i j}$ is the fractional concentration of species $i$ in the emissions from source $j ; S_{j}$ is the total mass concentration contributed by source $j$; and $p$ is the number of sources, and $n$ is the number of species, with $n \geq p$.

There is no single goodness-of-fit parameter but a set of measurements which can assess the model's reliability. A T-statistic (Tstat) value less than 2.0 indicates that the source contribution estimate is at or below a detection limit. The chi-square, $\mathrm{R}$-square, percent mass, and fit measure are performance measures for the least squares calculation. The value of chi-square less than 4.0 is acceptable. $\mathrm{R}$-square ranges from 0 to 1.0. The closer the value is to 1.0 , the better the source contribution estimates explain the measured concentrations. Percent mass should equal to $100 \%$, though values ranging from $80 \%$ to $120 \%$ are acceptable. When the abso- lute value of this ratio under the column labeled Residual/ Uncertainty exceeds 2.0, the residual is significant. If it is positive, then one or more of the profiles is contributing too much to that species. If it is negative, then there is an insufficient contribution to that species and a source or more may be missing. The analyses were done using EPA-CMB8.2.

\section{RESULT ANALYSIS AND DISCUSSIONS}

\section{Heavy metal assessment}

There are different kinds of mines intensively distributed at the upstream area of Maiweng River. In Yangchang River, light industry factories are mainly located in its upper catchment, while heavy industry ones, such as mechanical manufacture and chemical industry are mainly located in its lower catchment. There is no industry area at the upper Maxian River catchment and few light industry factories are located in its lower region. There is no industry factory in the Houliu River catchment. In this study, the factories surrounding to Hongfeng Lake that had direct effluents to it were treated as point sources.

The mean values of enrichment factors (EF) were calculated for each kind of heavy metal in the sediments from different source section and receptor (Table 2). In order to distinguish anthropogenic inputs from natural

Table 2. Mean values of enrichment factors for each metal in sediment

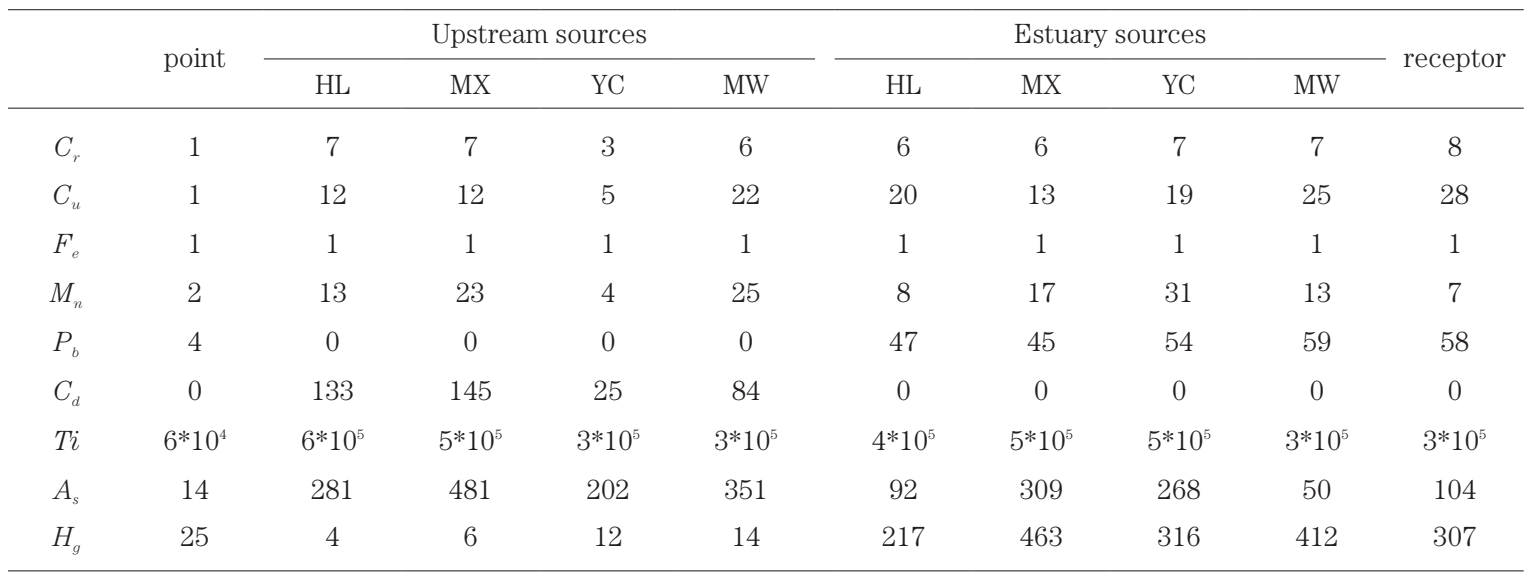

Bold means the enriched heavy metals

Table 3. Source apportionment for ambient sample and heavy metals

\begin{tabular}{lcccc}
\hline Estuary source combination & Houliu & Yangchang & Maiweng & point \\
\hline Hongfeng lake & $60 \%$ & $0 \%$ & $29 \%$ & $11 \%$ \\
$T_{i}$ & $57 \%$ & $3 \%$ & $36 \%$ & $4 \%$ \\
$A_{s}$ & $64 \%$ & $3 \%$ & $28 \%$ & $5 \%$ \\
$H_{g}$ & $37 \%$ & $3 \%$ & $58 \%$ & $2 \%$ \\
\hline Upstream source combination & Houliu & Yangchang & Maiweng & Maxian \\
\hline Hongfeng lake & $39 \%$ & $16 \%$ & $45 \%$ & $0 \%$ \\
$T_{i}$ & $33 \%$ & $21 \%$ & $43 \%$ & $3 \%$ \\
$A_{s}$ & $21 \%$ & $16 \%$ & $60 \%$ & $3 \%$ \\
\hline
\end{tabular}


sources for a given heavy metal element, EF estimates should be equal to or larger than 10.0. The EF values calculated for $C_{r}, C_{u}, F_{e}, M_{n}, P_{b}$ were relatively low that indicated limited inputs from the man-made sources. The EF values calculated for $T_{i}$ and $A_{s}$ were high that was caused by the inputs from the $T_{i}$ and $A_{s}$-enriched crustal rocks in Hongfeng Lake. The results of sample analysis showed that $C_{d}$ concentrations were high in the upper tributaries and low in the estuaries. This was caused by the enrichment of $C_{d}$ in the upper streams. On the contrary, $H_{g}$ concentrations were higher in the estuary sites, which indicated the distributions of man-made sources in the estuary area.

\section{Source identification}

In the fitting process, colinearity was identified by the CMB model between source profiles from the same tributary of Hongfeng Lake when simultaneously entering these source profiles to CMB model as source combination. So source profiles sampled from the same tributary at the different sections should be separated into different source combinations. With respect to the variation of enrichment factors between upstream sites and estuary sites, the profiles in the two areas were finally separated into two source combinations, the upstream combination and the estuary combination. The upstream combination included upstream sites of Houliu River (HL), Maxian River (MX), Yangchang River (YC) and Maiweng River (MW). The estuary combination included the individual point sources (Point) and estuary sites of HL, YC and MW. In addition, colinearity was also identified in the profiles of measured point sources due to the similar productive process and limited species. So the profile of mechanical manufacture was selected as the representative of point sources for further estimates labeled as point in the estuary combination.

\section{CMB model results}

Table 4 gave the $R^{2}$ values along with the range of ratio R/U and Chi Square values. The results from the source apportionment calculations showed strong agreement with each other for most of the ambient samples with an absolute value of ratio R/U under 2.0 and a value of Chi square under 4.0. The results were acceptable for a fitting solution.

The upstream source combination for Hongfeng Lake source apportionment showed that the most important contributor was Maiweng River (45\%) due to the intensively distributed mines. Houliu River and Yangchang River contributed $39 \%$ and $16 \%$, respectively. The estuary source combination (shown in Table 2) for h2-8 source apportionment showed that Houliu River and
Maiweng River were the most important pollution sources, which contributed about $60 \%$ and $29 \%$, respectively (see Figure 2). The contribution of estuary to Hongfeng Lake was higher than the upstream area, which was caused by the point source discharges from the estuary. The absolute contributions of Maiweng River and Houliu River steadily increased from the upstream areas to lower estuaries, while their contribution proportions decreased. On the contrary, the contribution proportion of Houliu River increased together with its absolute contribution, which showed the increase magnitude of Houliu River from upstream to lower estuary was higher than other tributaries.

However, the contribution value of Houliu River was increased in the estuary combination with respect to the increased total sediment quantity. That Figure 3 showed the source apportionment results of man-made and heavily enriched heavy metals identified in the sediments. In the upstream watershed, Maiweng River contributed about $43 \%$ and $60 \%$ of $T_{i}$ and $A_{s}$, respectively. While their controllers change d to Houliu River when $T_{i}$ and $A_{s}$ were transported downstream. Houliu River contributed 57\%

A
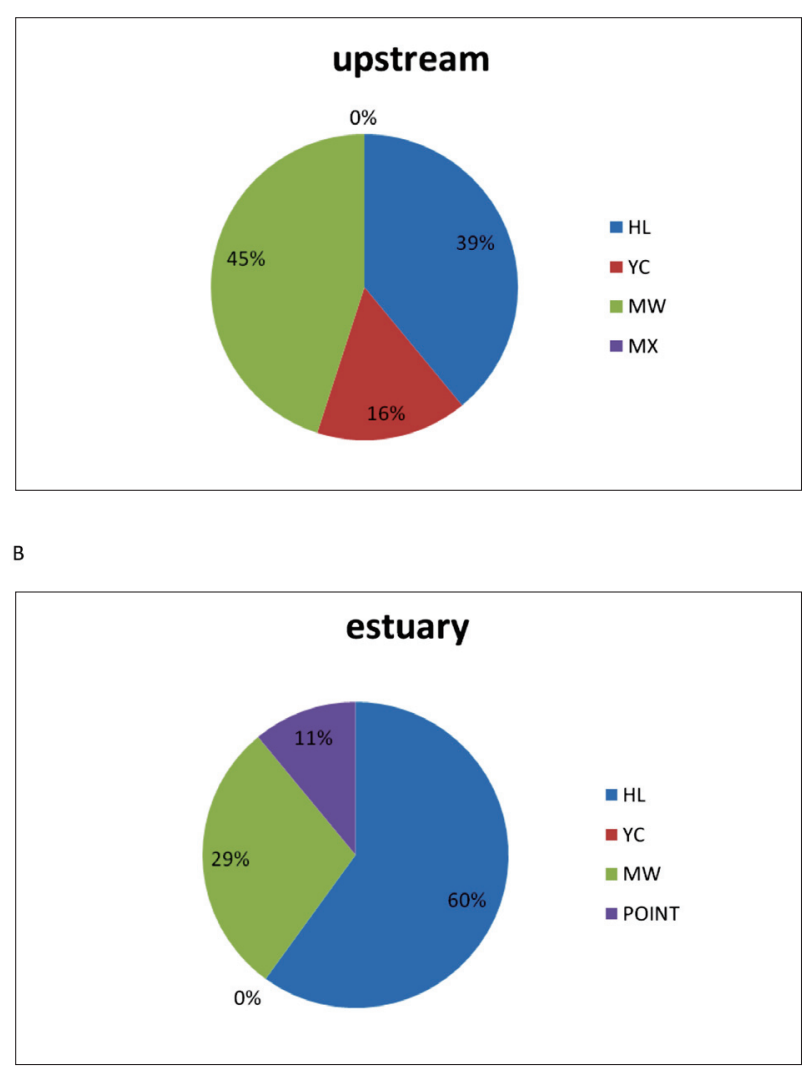

Fig. 2. Sediment source apportionment of Hongfeng Lake based on metal profiles.

Table 4. CMB performance statistics

\begin{tabular}{lcccc}
\hline combination & R SQUARE & \%MASS & CHI SQUARE & RESIDUAL/UNCERNTAINTY \\
\hline upstream & 1 & 101.3 & 1.29 & 0.9 \\
estuary & 1 & 102.2 & 6.85 & 1.6 \\
\hline
\end{tabular}


A

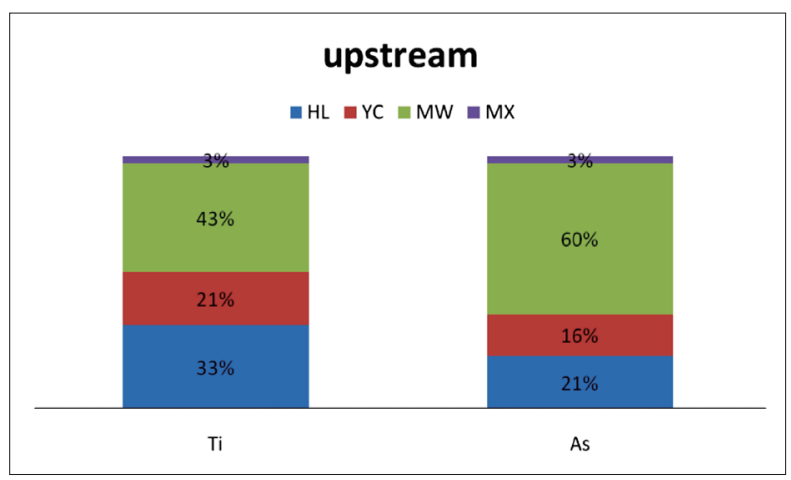

B

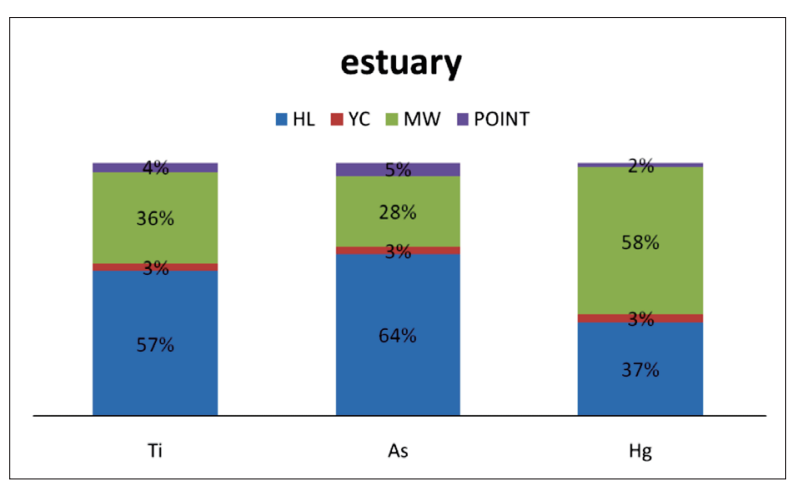

Fig. 3. Source apportionment of enriched heavy metal in upstream source combination and estuary source combination.

and $64 \%$ of $T_{i}$ and $A_{s}$, respectively. The main source of $H_{g}$ in sediment was from the estuary of Maiweng, which contributed about 58\%. Therefore, strict controls of $T_{i}$, $A_{s}$ and $H_{g}$ should be focused on the Maiweng estuary and its surrounding land use. Though the EF value of $C_{d}$ was high in the upstream area, it could not be apportioned because the receptor had low concentration. This revealed that the depositing speed of $C_{d}$ was quick so it could not be transported for long distance. Therefore, the concentration of $C_{d}$ in sediment reflected the impacts of the surrounding land uses.

\section{CONCLUSIONS}

In this study, Houliu River was identified as an important source contributing to Hongfeng Lake according to their same contribution trends. The high contribution ratio (45\%) of Maiweng River to the upstream source combination was attributed to the intensive distribution of mines in the upstream watershed. The contribution of point source (10\%) was stable over time.

Through the case study in the Hongfeng Lake, the CMB model was found to be suitable for source apportionment of pollutants that deposited in the lake sediment.

\section{ACKNOWLEDGEMENTS}

This research is supported by the Chinese National Special Science and Technology Program of Water Pollution Control and Treatment (2009ZX07419-003) and Kyushu University Research Institute for East Asia Environment.

\section{REFERENCES}

Burton, G. A., 1992 Sediment toxicity assessment. Lewis Publishers, Chelsea, MI, p. 457

Cooper, J. A. and J. G. Watson Jr., 1980 Receptor oriented methods of air particulate source apportionment. J. Air Pollut. Control Assoc. 30(10): 1116-1125

Fay, J. A. and J. J. Rosenzweig, 1980 An analytical diffusion model for long distance transport of air pollutants. Atmos. Environ. 14: 355-365

Gordon, G. E., W. R. Pierson, J. M. Daisey, P. J. Lioy, J. A. Cooper, J. G. Watson, and G. R. Cass, 1984 Considerations for design of source apportionment studies. Atmos. Environ. 18(8): $1567-1582$

Hopke, P. K., 1985 Receptor Modeling in Environmental Chemistry. Wiley-Interscience, New York

Kelley, D. W. and E. A. Nater, 2000 Source apportionment of lake bed sediments to watersheds in an Upper Mississippi basin using a chemical mass balance method. 4: 277-292

Larsen, R. K. and J. E. Baker, 2003 Source apportionment of polycyclic aromatic hydrocarbons in the urban atmosphere: a comparison of three methods. Environ. Sci. Technol. 37: 1873-1881

Lee, H. S., R. A. Wadden and P. A. Scheff, 1993 Measurement and evaluation of acid air pollutants in Chicago using an annular denuder system. Atmos. Environ. A Gen. Top. 27A(4): 543553

Prange, J. A. and W. C. Dennison, 2000 Physiological responses of five seagrass species to trace metals. Mar. Pollut. Bull. 41 327-336

Radenac, G., D. Fichet and P. Miramand, 2001 Bioaccumulation and toxicity of four dissolved metals in Paracentrotus lividus sea-urchin embryo. Mar. Environ. Res. 51: 151-166

Salomons, W. and Fostner, V., 1984 Metals in the Hydrocycle, pp. 63-93

Gummeneni, S., Y. B. Yusup, M. Chavali and S. Z. Samadi 2011 Source apportionment of particulate matter in the ambient air of Hyderabad city, India. Atmospheric Research, 101: 752764

Su, S., J. Zhi, L. Lou, F. Huang, X. Chen and J. Wu 2011 Spatiotemporal patterns and source apportionment of pollution in Qiantang River (China) using neural-based modeling and multivariate statistical techniques. Phys. Chem. Earth, 36: 379386

UNEP, 1982 Reference Methods for Marine Pollution Studies 14

UNEP, 1985 GESAMP, cadmium, lead and tin in the marine environment. UNEP Regional Seas Reports and Studies 56

Wang G. Q., B. L. Xue, J. S. Yu and K. Otsuki 2011 Continuous modeling of infiltration rate for the management of sprinkler irrigation. J. Fac. Agr. Kyushu Univ., 56(1): 157-161

Wang G. Q., P. Hapuarachchi, H. Ishidaira, A. Kiem and K. Takeuchi 2010 Grid based distributed model for simulating runoff and soil erosion from a large-scale river basin. Hydrol. Process., 24(5): 641-653

Yamamuro, M. and Y. Kanai, 2005 A 200-year record of natural and anthropogenic changes in water quality from coastal lagoon sediments of Lake Shinji, Japan. Chem. Geol. 218 51-61 